\title{
Female Survivors of African Wars Dealing with the Past and Present
}

\author{
Nimo Bokore, BSW, MSW, RSW \\ Women's Health in Women's Hands Community Health Centre \\ 2 Carlton Street, Suite 500 \\ Toronto, Ontario, M5B 1J3, Canada \\ Website: http://www.whiwh.com
}

\begin{abstract}
Over-stressed and over-burdened, Somali women in Canada provide for family members while heading their households in new and sometimes unfamiliar cultural and social landscapes. Affected by previous ordeals and the strains of relocation (Danso, 2002), time and again past traumas and settlement experiences intersect, producing new barriers that these women struggle to overcome (Baines, 2007, p. 108; Galabuzi, 2002). As a result, many display classic signs of Post Traumatic Stress Disorder (PTSD) and anxiety (Acosta, 2004; DSMV, 2009). Yet there is an absence of Canadian literature documenting these issues for Somali women in this country. Thus, based on stories, counselling sessions and community meetings, I present this paper as an introduction to their experiences. To better understand these barriers, I examine the impacts of prolonged trauma, the women's experiences in Canada and on the transference of trauma from mothers to children and adolescents. Finally, I explore the health seeking behaviours, mental wellbeing and socioeconomic status of Somali women within the context of culture and religion.
\end{abstract}

Keywords: Pre-Migration traumas and post-migration outcomes, Trauma transference, Religion, Culture, Mental health, Overall wellness, Community resilience 


\section{Introduction}

This article examines the impact of prolonged trauma on female survivors of wars and resettlement stressors that may contribute to life long illnesses and poverty. Using my personal experiences as a survivor of East African wars and as a member of the Somali community, this article will explore the pre and post migration experiences of survivors. Recent reports from the Horn of Africa depict the bleak picture of a region in crisis. A lack of formal governance, long standing tribal wars, increasing reports of pirating, kidnapping and mass displacement are some of the main factors compounding the current turmoil in the East African nation of Somalia. In response to ubiquitous pressures, many Somalis have migrated to Canada to escape war, poverty and violence. According to Statistics Canada's 2006 Census Report, the Somali Diaspora has grown to over 33,725; however ethno-specific agencies indicate that this number may be higher (York Community Services [YCS], 1999).

Since their initial arrival in the late 1980s and early 1990s, Somali immigrant families, mostly consisting of female-headed households began settling in lower-income racialized neighbourhoods (Danso, 2002). They became one of the socioeconomically disadvantaged Canadian communities, experiencing disproportionate levels of poverty, violence; youth drug addiction, homelessness, inadequate housing, discrimination, and inadequate health care (Danso, 2002 \& Ornstein, 2006). According to Dennis Raphael (2008, p. 2),

"Social determinants of health are the economic and social conditions that shape the health of individuals, communities, and jurisdictions as a whole. Social determinants of health are the primary determinants of whether individuals stay healthy or become ill. It is about the quantity and quality of a variety of resources that a society makes available to its members."

This report and others links these issues to individual and community health (Beiser, 2005; Galabuzi, 2002; Latkin \& Curry, 2003; Raphael, 2004). Listening to community complaints about structural disparities I started asking specific questions during individual meetings at a Toronto Community Health Centre (CHC) where I work serving black women and women of colour. Concerned about the barriers to accessing services, I asked the same questions to individuals as a well as groups of women during a health promotion outreach program. I asked the following three questions to explore their experiences:

To identity systemic or cultural barriers, I asked the reasons as to why they decided not to seek assistance from providers

To identify their specific needs, I asked what would have made their settlement experience more successful

To identify the impact of trauma and current stressors in their lives, I asked what would make a difference in their health

The themes that emerged include: pre-migration traumas and post-migration outcomes, violence, mental health, overall wellness, coping mechanisms, and community resilience. During community meetings the women often looked back on how they got to where they are today and discussed their history of repression, colonization and displacement. 


\section{Somali History}

The Horn of Africa is made up of Somalia, Ethiopia, Eritrea, and Djibouti. Historically, Somalia has been a strategic spot for global powers initially interested in securing coaling stations and, later, oil rights throughout the Arabian Peninsula. Using the divide and rule approach, early Western colonizers separated the country into five regions: Northern Somalia (or British Somaliland), Southern Somalia (ruled by Italy), Northern Kenya, Ethiopia and Djibouti (ruled by the French) (Rapando, 2005). Throughout the Cold War and during the 1977-1978 Ogaden War between Ethiopia and Somalia, world powers continued to fracture the region (Duyvesteyn, 2000). Conflicts such as the Ogaden war, followed by the fall of the Somali government in the early 1990s, have prompted mass internal and external displacement of Somali people. A lack of governance in Somalia since the early 1990s and regional power struggles between Ethiopia and Eritrea have also contributed to ongoing tensions. According to the 2009 Refugee International Report, there are now "approximately 1.3 million internally displaced Somalis in Somalia and over 400,000 Somali refugees in neighbouring countries”. While Somali immigrants escape the physical threats of War and conflict, as well as the atrocities of refugee camps when they arrive in Canada, a new series of psychological challenges and settlement barriers emerges instead.

\section{The Pre-Migration Experience of Somali Women}

Somali societies maintain strong clan-based relationships that have been established to provide guidance, support and community. Speaking from my own experience as a woman of Somali and Ethiopian descent, who grew up and lived within traditional Somali society rules, I can attest that these communal relationships are often forged through shared religion, reinforced through tribal rules and similar political views. Contrary to the fact that the majority of the Canadian Somali families now consist of female-headed households in Diaspora, the Somali tribes are mostly patriarchal. These tribes operate within a democratic system that consists of a council or "shir" (in Somali language), organized by men who are leaders in the community. In these councils women often do not enjoy the same rights or privileges as men. While there is no clear gender equality, the women do have freedom of self-expression, especially within the household, where they hold the greatest power. Women have a strong support system within their own community. These systems are strengthened and developed at an early age through friendships. Traditionally, friendship is gender specific; men, women and children will only spend time with companions of the same sex. However, the prolonged regional war in Somalia has destroyed many traditional linkages, disrupting close relationships and the support of friends and extended family members, resulting in tribal-based divisions and health concerns (Bhui, Craig, Mohamud, Warfa, Stansfeld, Thornicroft, Curtis, \& McCrone, 2006). Somalis are a poetic society passing their values, culture, life skills and nationalism through story telling as well as poems. The prolonged war destroyed many such traditions including the passing of a story from father to son. Therefore boys develop a misinformed sense of tribalism and other vulnerabilities. As a result, the women expressed their fear for their sons as they became increasingly vulnerable to other influences. Community reports show that tribal divisions are now more common and linked to the Canadian experience of an increasing rate of youth gang violence (Aw-Osman, 2008; 
Latkin, \& Curry, 2003).

My own personal history is filled with narratives of colonization, liberation, deportation and displacement. My parents met in Eastern Ethiopia, in my mother's home country. My father was a respected religious and academic leader in his native land of Somalia. However, he was deported to Ethiopia by the British Colonial government who, at the time, ruled the Northern part of Somalia. His crime was advocating for education for his fellow Somalis and fighting for national unity or "Somali Wayn" (which in Somali means "Greater Somalia”). Years later, he was deported back to Somalia by the Ethiopian government, leaving behind my mother and family. When the military regime in Ethiopia started a systemic ethnic cleansing campaign against Eastern Ethiopian tribes in the early 1980s, my family was at risk again. To escape the threat of death, I escaped to neighbouring Djibouti, and then migrated to Somalia, but due to the start of political destabilization in Somalia, I fled to Italy. My story is not unique. Many immigrants from the Horn of Africa have lived through a similar experience of family separation and household rupture. There are a number of research and literatures regarding trauma and life stressors affecting the wellness and mental health of immigrant communities (Weiss, Jadhav, Raguram, Vounatsou, Littlewood, 2001; Raphael, 2002, 2004; Groleau, Pluye, Nadeau, 2007). However, there is presently a gap in Canadian research and literature exploring Somali women's experiences of long term displacement, trauma and settlement barriers.

\section{Impact of Prolonged Trauma}

Due to prolonged displacement, the majority of Somali women have never had the opportunity to continue their education. They are at a disadvantage from benefiting from programs created for other immigrants such as internationally trained professionals. The barriers to foreign trained professionals or skilled immigrants are over researched by academics, creating further bridging programs which assist in their successful integration. Somali women are unable to access these programs due to their level of literacy and therefore feel excluded.

Another impact of prolonged trauma deals with family structure. Somali family structures are traditionally clan-based patriarchal units, however, war and displacement have created here in Canada a sub-culture of female-headed households within Somali communities. Over the years, women have increasingly taken on the responsibility of caring for their families, as refugees in Canada or in refugee camps scattered throughout East African nations. Their experience of long term violence, displacement, emotional and physical traumas, has destroyed Somalis strong clan-based support systems, contributing to marriage breakdowns, behavioural problems in children and a growing rate of youth gang violence in Diaspora communities.

This year, while conducting a mental health presentation for a group of Somali women living in Toronto, one of the women asked me: "Will I ever recover from the nightmares of war and the horrors of refugee camps?" She wanted to know if therapy would help her sort out her nightmares. Although I had no direct answer to give her, this inquiry led me to reflect on my own trauma experience and to a deeper exploration of the experiences of other refugee 
Somali women. I share with them the experience of witnessing human rights abuses including unjustifiable incarceration, combat, torture, physical and sexual abuse, the murder of family and friends and the vicious xenophobia of host country residents fed up with the encroachment of refugee camps. Disclosure of personal histories by a number of participants in the group led to further sharing of lived experiences, creating a safe space for dialogue, hope and encouragement. Several of the women told me how they distanced themselves from their negative memories for years, by suppressing their emotions as a method of coping with past traumas. While the women could not name the phenomenon they were experiencing, the emotions and memories they discussed embodied classic symptoms of Post Traumatic Stress Disorder (PTSD)(Note 1)

\subsection{Gender-Based Trauma}

Somali women are not spared the popular method of violence "rape" designed to punish or overpower the weak or as a form of ethnic cleansing (Maxamuud, 2006; UNICEF, 1997), but there is a culture of silence that shrouds the experiences of rape victims. Within Somali society, the practice of "hisaut" requires that women show a sense of modesty and shame. Any discussion of reproductive health or sexuality is therefore prohibited by this custom. The women with whom I spoke felt that "hisaut" fostered a sense of humiliation and disgrace among victims of sexual assault. Violated women, especially young girls, are encouraged to hide their experience from members of the community. As described by my clients, mothers who are aware of their daughter's situation will often encourage infibulation or female genital mutilation (FGM) a procedure that disguises the impact of rape. This is due to Somali culture, with a perceived expectation of young women to remain virgins until marriage. While there is much controversy surrounding this practice, mothers will often promote FGM to protect their daughters from further dishonour.

Overall, female subjugation appears to contribute negatively to health seeking behaviours within the Somali community. Frequently, I will meet with women who have delayed getting treatment for Sexually Transmitted Infections (STIs), including HIV, until they are in the later stages of the disease. As elders from a clan were previously viewed as a trusted source for traditional healing methods, many immigrant Somali women have difficulty understanding and accepting Western pharmaceutical approaches. Language difficulty and unfamiliarity of treatment options further contributes to the health seeking behaviours of the Somali women.

\subsection{Dealing with Repressed Feelings}

Somali clients come to discuss why they are re-experiencing past distressing events through imagery and recurring nightmares, why they sometimes have angry outbursts, and why they are excessively vigilant. They describe how past distressing events not only have a negative impact on their own well-being, but also put a strain on their relationships with their children. In some cases, women talk about their children, who are old enough to have lived through the traumas of war and refugee life, having adjustment difficulties here in Canada, adding an additional layer of complexity to their settlement experience. When speaking with the women, distress is still audible in their voices as they recount their lives as refugees, protecting their young children, while witnessing the horrors of war and camp conditions. My own family 
has shared a similar past: settling in UN refugee camps and migrating to countries far from home in search of security and safety. The children of Somali immigrants, my own included, still remember what they saw at a young age, atrocities such as climbing over dead bodies during escape, hiding from bullets, and leaving other family members and friends behind. Undoubtedly, these experiences have an enduring impact on mothers and their children, emerging in various ways that influence their health and wellbeing, their behaviours and their life choices. For many Somali youth living in Canada, this leaves them searching for guidance and direction from culture-specific groups, religious affiliates or community organizations.

\section{Post-Migration Barriers}

Increasingly, popular news media in Canada have been depicting the growing number of Somali youth involved in street gangs, reporting on murders linked to drugs and gang-loyalty (Aw-Osman, 2008). Most women that I speak with are confused and frustrated by the violence their children experience in Canada. For a substantial number of immigrants and refugees, Canada is regarded as a safe haven for their families. During our discussions mothers talked about their fear of losing their sons to gangs and religious extremists who are trying to use their sons for their own benefit. In response to the gang-activity and violence encountered in Canada, many mothers become distressed, describing feelings of powerlessness. They dread the repercussions of losing their children to street gangs or extreme religious movements that recruit youth for the purpose of strengthening jihad and religious bases in Eastern Africa. During one particular discussion, the topic moved to the reports on the missing "Somali boys from Minneapolis, Minnesota, USA." These missing boys are suspected of joining the terrorists' factions in Somalia (NPR, 2009).

\section{Transferring Trauma Experience to Children}

As hypothesized by theories of intergenerational transmission of trauma, the stressors of migration and past ordeals are transposed from one generation to the next (Schwerdtfege \& Goff, 2007). This phenomenon is manifested in behaviours and coping strategies of some of the Somali youth with whom I spoke (Bhui et al., 2006; Schwerdtfege \& Goff, 2007). Reports on the community show that an estimated $70 \%$ of Canadian-Somali youth exhibit the effects of trauma, resulting in behavioural problems, addictions, gang membership and even participation in extremist religious groups that build on youth vulnerability and impressionability as a recruitment strategy (Aw-Osman, 2008; YCS, 1999). Further studies have shown that children who have experienced life in a refugee camp, especially those presently in their teens or twenties, encounter difficulties adapting to school life and socialization in their adoptive countries (Bhui et al., 2006; Danso, 2002; UNICEF, 1996; YCS, 1999).

In Canada, higher education is seen as a necessary step for better job opportunities and integration into the labour market (Die, Mazzuca, Mclsaac, Zine, 1997, pp. 227-228; Galabuzi, 2001; Sakamoto, 2007). Moreover, education helps to overcome impoverishment which is recognized as a social determinant of health (Galabuzi, 2002; Raphael, 2002). Michael Ornstein's 2006 report, shows that one-third (33\%) of Somali youth between 25 and 
34 dropped out of high school. These disproportionately high statistics have been linked to a number of factors including: language difficulties (Brown, 2006), early trauma experiences (Bhui et al., 2006; YCS, 1999) and existing disparities within the educational system (Die et al., 1997, pp. 150-168). As education is a way of improving one's socio-economic status and creating future opportunities, the consequence of disproportionately high drop-out rates within the Somali community is that the cycle of poverty is reinforced (Galabuzi, 2001).

In the process of discussing current settlement obstacles and the difficulties faced by Somali-Canadian boys, the mothers in my group began to reveal their frustration with the education system. With financial cut-backs within the education system, more of the responsibility of educating the young is left to families. Mothers who may be struggling with their own literacy issues have far greater difficulty assisting their children with schoolwork at home (Die et al., 1997, p. 58; Campbell \& Gregor, 2002, p. 11). As a result, their children are dropping out of school and often entering the criminal justice system at an early age (Aw-Osman, 2008). A number of mothers I spoke with explained that the youth, embarrassed by the exclusionary education system in Canada, were experiencing feelings of helplessness. The youth, frustrated and isolated, combat their feelings of powerlessness through gang-membership and criminal activities (Aw-Osman, 2008). Their quick solutions to gain power, through participation in violent activities, are presenting tragic consequences for the Canadian Somali community (Aw-Osman, 2008; Galabuzi, 2002; Kinzie, 2004; Lynam, \& Cowley, 2007). In our group discussion, one women credited fear and a need for protection as to why Somali boys join these groups. She then talked about experiencing vicious xenophobia while in African refugee camps and from her neighbours in Canada. She said,

"I escaped to Kenya in 1991. One day the children from the camp, my son included had a fight with the local children. Later that evening, while we were sleeping, a fire broke in the area surrounding the camp. I escaped in the middle of the night to another camp caring my children. I still have nightmares of being burned alive.”

She also spoke about her settlement experience in Canada and how her son started to have difficulties with other children and school. A few weeks after our discussion, her fears were realized when I saw a news article about her son's murder. He was stabbed to death by a group of young men living in the Toronto west area.

\section{Health-Seeking Behaviours}

\subsection{Religion and Culture}

Religion and culture has been the strength of Somalis for centuries. It also became a factor preventing their use of the available and conventional allopathic health care system. They prefer and seek out traditional homeopathic means of healing when it comes to their health and wellness. According to a Community Health Assessment report produced by York Community Services (YCS), illness is not perceived as a negative outcome within Somali communities (1999). Instead, it is believed that ailments should be accepted with dignity as they are an opportunity "to be penalized for sins and gain forgiveness from God". I grew up understanding this and it is still perceived by others that complaining about ill health is 
inappropriate or poor behaviour. Somalis are among the most homogeneous populations in Africa, sharing among others similar health and well being practices. Nearly all Somalis practice Sunni Islam and they come from clan based groupings that are often interconnected, creating an important social unity. Prayer is believed to have special healing properties when guided by religious leaders. As a result Somalis travel long distances to seek religious healers. The women I spoke with said they prefer to seek out religious healers, as opposed to allopathic healers; accordingly religion is still the preferred practice among Somali Canadians. A number of women talked about their family members who returned back home to their country of origin, or to refugee camps in Africa, to receive prayer treatments.

\subsection{Practicing Pre-Islamic Traditions}

Somali culture also includes some remnants of pre-Islamic traditional healing practices (Bhui et al., 2006). Practitioners perform operations such as, bloodletting, scarification, cauterization and teeth-pulling. Cauterization is a common therapy for treating diseases such as Hepatitis A, B, C and parasites; the practice is based on the belief that disease and fire cannot coexist. I grew up watching tonsillectomies which are performed by first sterilizing simple instruments in a fire. I still remember when this procedure was performed on me as a child, a true introduction into healing and cultural practices. Healers also use therapeutic massage and natural materials, such as wood and plant extracts, to treat fractures which I personally received and benefited from.

However, prayers are the strongest of all these traditional methods of healing and are still the most commonly practiced healing methods within Canadian Somali communities (YCS, 1999). Islam plays a major role in the lives of many Somali immigrants, influencing their views of illness and recovery. It is a common belief that ultimately every illness occurs under God's will, even though some diseases are thought to be caused by bad spirits and the "Evil Eye” or witchcraft. Prayers, herbs and other forms of prevention are a part of the healing for all (Bhui et al., 2006; YCS, 1999).

Somali traditional healers preach that mental illness and other diseases are mainly caused by the devil or "Jin". Seeing images or hearing voices are also considered normal in the community. Therefore mental illness at its beginning is tolerated, allowing individuals with abnormal behaviour to be forgiven. Since health care services are scarce back home and in refugee camps, these beliefs become a helpful coping mechanism for the community. However, for the past twenty five years, religion in Somali communities around the world has been undergoing a profound ideological and ritual change, moving away from tolerant Islamic orders with traditional practices to stricter Islam that follows a conservative interpretation of the religion. While this process of adaptation is going on within the Somali communities, the women I spoke to told me that most of them still rely on healing practices carried out within the context of old beliefs. When I asked if they also use the available health care system in Canada, some of the women said they use the traditional method when the medication does not work for them. They also acknowledge that some community members delay seeking help by using the traditional method first, then going to medical teams, (such as physicians, nurses and other health care professionals) only if the traditional medical 
practitioner fails in his/her performance.

In a recent conversation I had with one of the leading Somali Psychiatrists in Ontario, Dr. Abdishakur Sheikh Ali Jowhar, we discussed Somali healing methods and medical misconceptions and Dr. Jowhar said,

“Causes of illness, including mental illness, are defined by Somali culture differently than the mainstream society. Some Somali community members believe that mental illness is caused by witchcraft. These groups do not believe that mental illness is a disease of the brain that can be cured by medication and therapy”.

Somalis are at odds with holding on to traditional practices, yet on the other hand, they are encountering barriers when trying to access Canadian health care information. For example, there is no direct translation for "depression" in the Somali language. Similarly, stress is not recognized and individuals affected by it seek help at a later stage when it starts to trigger other health issues or after all other traditional healing venues are exhausted (Jowhar, 2009). Due to language difficulty and cultural differences, there are some members of the community who do not understand or accept western type intervention such as pharmacology treatment or counseling.

Referrals to mental health services are often misunderstood because of language or the unfamiliarity with the health care system in Canada. Dr. Jowhar said, "People came to see me after they have been suffering with their illness for a longer time than necessary. Lately, there is also an increase in the number of depression, post traumatic stress disorder, anxiety and depression cases in Somali communities.” Few health care professionals are familiar with Somali traditional treatments that often delay illness diagnosis and asking patients the right questions (Jowhar, 2009). Family care givers often delay treatments, instead using medications from traditional healers such as herbs, wearing of amulets for curing the "Evil eye", curses, witchcraft and fumigation to heal certain illness or use these methods in combination with pharmacology. This unmonitored combination can be dangerous. There are additional gender based health issues within the community. Substance abuse is on the rise among men and youth especially the use of the traditional herb "Khat" and other drugs such as alcohol, crack and cannabis (Bhui et al., 2006). Currently, Canadian health professionals who are unfamiliar with the Somali culture may refrain from questioning clients about substance abuse, due to assumptions based on the Islamic restriction on drugs and alcohol. This further serves to perpetuate the cycle of substance abuse.

\section{Recovery Based on Anti-Oppression Prospective}

Treatment models practiced in mainstream agencies based on a mono-cultural, biomedical, western format (Heinonen \& Metteri, 2005, pp. 170-72) are not benefiting ethnic specific communities such as Somali women who are dealing with language limitation, cultural and religious barriers. These health recovery models based on "one size fits all” are ignoring the diversity of culture and needs of these new Canadian groups. It is essential to recognize a difference even within immigrant communities. Women are not homogeneous. The impact of: gender, diversity, migration condition/status of immigration and pre-migration trauma, affects 
each group differently and must be taken into account while advocating or creating programs (Bhui et al., 2006; Galabuzi, 2001). After recognizing the psycho-socio-economic and cultural challenges that are affecting the health and well-being of Somali women, I argue that there is a need for more effective community health promotion programs targeting Somali women and others with similar situations. There is a need for programs designed to educate the importance and benefits of early help-seeking methods and safe co-usage of pharmacology with traditional healing methods. For example, prayers are the strongest of all traditional methods of healing for Somalis. Acknowledging and supporting patients in this part of the tradition will increase the trust they have for their service provider and will open the doors to better health care usage.

\section{Recommendations}

From my many discussions with clients, I have created the following recommendations:

Service providers in Canada need to recognize the many steps of settlement and the adjustment period for survivors of wars.

Service providers also need to understand the strengths and the different circumstances of immigrants. Recognizing these factors, and the role they play in each individual's life, will help health care professionals to design a recovery model or deliver programs that are accessible and effective.

Service providers working with female survivors of war such as Somali women need to consider a better integration of cultural and socio-political approaches with foundational aspects of anti-oppression, feminist based intervention.

Government health agendas should expand beyond "one size fits all” resettlement policies and expand funding to more health promotion programs toward improving the daily lives of traumatized women and their families.

\section{Conclusion}

Somali women's lives are full of struggle, resistance and resiliency. They survived the gendered consequences of war, including the physical and psychological violence of rape and terror. They are dealing with raising children in unfamiliar social and cultural territories that often presents its own challenges and difficulties. They are dealing with a consistent comparison to other immigrant's settlement successes, which impact upon their own self-esteem and self-worth. Somali women are resilient and they have been surviving a strong gender based nomadic culture for centuries. They survived physical and emotional trauma in refugee camps and during misplacement. They are still struggling to learn new languages and raise their children with the little resources they have. For example, you see some of these women repeatedly taking the same English classes trying to learn the language. Going to the same class for years requires strong determination and demonstrates their resiliency to survive. Working in the field, there is a lack of awareness regarding differences of immigration situations and how it impacts the resettlement process. It is important for service providers to recognize the trauma, intensity of loss and sadness these women experienced 
before commenting or designing health prevention programs. Also, not recognizing specific community issues will not only contribute to the continued cycle of racism and oppression but will further increase the damages for which service users may be seeking help.

\section{References}

Acosta, Sabina (2004). Responding to the Needs of Women Who Survive Torture: From Silent Torment to Speaking Out. Canadian Centre for Victims of Torture, CVT. [Online] Available: http://www.ccvt.org/responding.html

Aw-Osman, Farah (2008, December 18). Somali Youth: Stop the Violence. Wardheernews.com. [Online] Available: http://wardheernews.com/Articles_08/December/18_somali_youth_farah.html

Baines, Donna (2007). DOING Anti-Oppressive PRACTICE Building Transformative Politicized Social Work, Winnipeg: Fernwood Publishing, p. 108.

Beiser, Morton (2005). “The Health of Immigrants and Refugees in Canada”, Canadian Journal of Public Health, Volume 96, pp. S30-S44.

Bhui, Kamaldeep; Craig, Tom; Mohamud, Salaad ; Warfa, Nasir ; Stansfeld, Stephen A.; Thornicroft, Graham; Curtis, Sarah and McCrone, Paul (2006). "Mental Disorders Among Somali Refugees: Developing Culturally Appropriate Measures and Assessing Socio-cultural Risk Factors”, Social Psychiatry and Psychiatric Epidemiology, Volume, 41, pp. 400-408

Brown, Louise (2006, June 23). Dropout, failure rates linked to language. The Toronto Star.

[Online]

Available: http://www.arts.yorku.ca/soci/goldring/clippings/dropout_rates_link_language.

Campbell, Marie and Gregor, Frances (2002) Mapping Social Relations: A Primer in Doing

Institutional Ethnography, Aurora, ON: Garamond Press, p. 11

Danso, Ransford (2002). From 'There' to 'Here': An Investigation of the Initial Settlement Experiences of Ethiopian and Somali refugees in Toronto. Netherlands: Kluwer Academic Publishers.

Dei, George J. Sefa; Mazzuca, Josephine; Mclsaac, Elizabeth and Zine, Jasmin (1997) Reconstructing 'Drop-Out': A critical Ethnography of the Dynamics of Black Student's Disengagement from School, University of Toronto Press, pp. 58, 150-168 \& 227-228

DSM-IV (2009). Post Traumatic Stress Disorder Diagnosis \& Criteria (309.81).Posttraumatic Stress Disorder Today. [Online] Available: http://www.mental-healthtoday.com/ptsd/dsm.htm

Duyvesteyn, Isabelle (2000). Contemporary War: Ethnic Conflict, Resource Conflict or

Something Else? London: Published by Frank Cass

Galabuzi, Grace-Edward (2001). Canada's Creeping Economic Apartheid: The Economic 
Segregation and Social Marginalisation of Racialised Groups. CSJ Foundation for research education, pp. 3-129

Galabuzi, Grace-Edward (2002). Social Exclusion: A paper and presentation given at The

Social Determinants of Health across the Life-Span Conference, Toronto, November 2002.

Groleau, Danielle; Pluye, Pierre; Nadeau, Lucie (2007). “A Mix-Method Approach to the

Cultural Understanding of Distress and the Non-Use of Mental Health Services”, Journal of Mental Health, Volume 16, Issue 6, pp. 731-741

Heinonen, Tuula \& Metteri, Anna (2005). Social Work in Health and Mental Health: Issues,

Development, and Actions, Toronto: Canadian Scholar’s Press Inc, pp. 170-171

Kinzie, J. D. (2004). "Some of the Effects of Terrorism on Refugees”, Journal of Aggression, Maltreatment \& Trauma, Volume 9, Issue 3/4, pp. 411-420

Latkin, Carl \& Curry, Aaron (2003). "Stressful Neighborhoods and Depression: A Prospective Study of the Impact of Neighborhood Disorder”, Johns Hopkins University Journal of Health and Social Behaviour, Volume 44, Issue 34

Lynam, Judith \& Cowley, Sara (2007). Understanding marginalization as a social Determinant of health. Critical Public Health: Routledge Taylor Francis

Maxamuud, Yaasmin (2006). Rape: A Conspiracy of Silence. Wardheernews.com.

[Online] Available: http://wardheernews.com/Articles_06/Jan/22_Conspiracy_Yasmeenl.htm

NPR (2009) Missing Somali Teens May Be Terrorist Recruits, [Online] Available: http://www.npr.org/templates/story/story.php?storyId=99919934

Ornstein, Michael (2006). Ethno-Racial Groups in Toronto, 1971-2001: A Demographic and

Socio-Economic Profile, Toronto: Institute for Social Research, York University.

Rapando, Murunga, G. (2005). "Conflict in Somalia and Crime in Kenya: Understanding the Trans-Territoriality of Crime”, African \& Asian Studies, Volume. 4 Issue 1-2.

Raphael, Dennis (2002). Poverty, Income Inequality and Health in Canada, Toronto: School of Health Policy and Management, York University

Raphael, Dennis (2004). Social Determinants of Health, Chapter 1 \& 15, Housing and Health, Toronto: Canadian Scholars Press

Raphael, D, (2008) Social Determinants of Health: Canadian Perspectives, Second Edition. Canadian Scholars' Press Inc.

Refugees International (2009). Somalia Field Reports. Refugees International: A Powerful voice for Lifesaving Action. [Online] Available: http://www.refugeesinternational.org/where-we-work/africa/somalia 


\section{Macrothink

Sakamoto, Izumi (2007). “A Critical Examination of Immigrant Acculturation: Toward an Anti-Oppressive Social Work Model with Immigrant Adults in a Pluralistic Society”, British Journal of Social Work, Volume 37, pp. 515-535.

Schwerdtfege, K. L. and Nelson Goff, B.S. (2007). "Intergenerational Transmission of Trauma: Exploring Mother-Infant Prenatal Attachment”, Journal of Traumatic Stress, Volume 20 Issue 1, pp 39-51.

Statistics Canada (2006). Ethnic origins, 2006 counts, for Canada, provinces and territories -

20\% sample data [Online] Available: http://www12.statcan.ca/english/census06/data/highlights/ethnic/pages/Page.cfm?Lang=E\&G eo $=$ PR \&Code $=01 \&$ Table $=1 \&$ Data $=$ Count $\&$ StartRec $=1 \&$ Sort $=2 \&$ Display $=$ Page

UNICEF (1996). Sexual Violence as a Weapon of War. The State of the World's Children 1996. [Online] Available: http://www.unicef.org/sowc96pk/sexviol.htm.

Weiss, Mitchell G.; Jadhav, Sushrut; Raguram, R.; Vounatsou, Penelope; Littlewood, Roland (2001). "Psychiatric Stigma Across Cultures: Local Validation in Bangalore and London”, Anthropology \& Medicine, Volume 8, Issue 1.

York Community Services (1999). A Study on the Mental Health Needs Of the Somali Community In Toronto. Prepared by Abdullahi S. Elmi. [Online] Available: http://ceris.metropolis.net/Virtual\%20Library/health/elmi1.pdf 